Article

\title{
An Interactive Decision-Making Method for Third-Party Logistics Provider Selection under Hybrid Multi-Criteria
}

\author{
Yumin Liu ${ }^{1}$, Peng Zhou ${ }^{1, *}$, Liyuan $\mathrm{Li}^{2}$ and Feng $\mathrm{Zhu}^{1}$ \\ 1 Business School, Zhengzhou University, Zhengzhou 450001, China; yuminliu@zzu.edu.cn (Y.L.); \\ zhufeng1994@163.com (F.Z.) \\ 2 Business School, Nanyang Institute of Technology, Nanyang 473000, China; liliyuan1990@foxmail.com \\ * Correspondence: wind-diao@foxmail.com; Tel.: +86-1863-851-3119
}

Received: 4 April 2020; Accepted: 1 May 2020; Published: 4 May 2020

\begin{abstract}
Due to the complexity and uncertainty of third-party logistics (3PL) provider selection circumstances, the research on the hybrid multi-criteria decision-making (HMCDM) method with fuzzy hesitation information is becoming more and more important. Based on symmetry principles, both the objectivity of the decision information and the subjectivity of decision makers' (DMs) preferences should be considered in the HMCDM method. In this paper, a novel interactive decision-making method to deal with the 3PL provider selection problem of hesitant fuzzy sets, intuitionistic fuzzy sets and real numbers is developed. We first investigate the positive and negative ideal solutions of the alternative and the satisfaction degree of the DMs under hybrid multi-criteria circumstances. Then, the interactive HMCDM models based on satisfaction degrees are established, which can use objective decision information to rank alternatives and, symmetrically, the preference information of the DMs is also taken into account. DMs can modify their preference information using the models and thus make the most reasonable selection of 3PL provider. Finally, the case analysis and sensitivity analysis show that the change of parameter and the setting of the satisfaction lower limit will not affect the optimal rank of alternatives, and the feasibility of the proposed method is confirmed.
\end{abstract}

Keywords: hybrid multi-criteria decision-making; interactive method; third-party logistics provider; hesitant fuzzy set; intuitionistic fuzzy set

\section{Introduction}

With the rapid development of logistics management and practice, logistics outsourcing has already become an important way to reduce cost and improve service level for most manufacturing enterprises [1,2]. Third-party logistics (3PL) providers are the main undertakers of logistics outsourcing activities, as they provide comprehensive logistics services for manufacturers and professional logistics providers [3]. Selecting the right 3PL provider as a business partner is the premise of logistics outsourcing for manufacturing enterprises [4].

In general, 3PL provider selection is a multi-criteria decision-making (MCDM) problem. Many of the main MCDM methods have been used in 3PL provider selection, including Delphi $[5,6]$, analytic hierarchy process (AHP) [7,8], fuzzy analytic hierarchy process (FAHP) $[9,10]$, grey relational analysis (GRA) [11,12], data envelopment analysis (DEA) [13,14], technique for order preference by similarity to an ideal solution (TOPSIS) [15-17], entropy weight-TOPSIS [18], and multi-criteria optimization and compromise solution (VIKOR) $[19,20]$. In addition, other methods including quality function deployment (QFD) [21,22], back-propagation neural network [23,24] and support vector 
machine (SVM) $[25,26]$ have been applied to solve the 3PL provider selection problem. The existing approaches can only be used to deal with the problem insofar as multiple criteria of 3PL provider selection have the same types of decision information, such as real numbers [5-7,9-16,18,19,25], interval numbers [27], triangular fuzzy numbers [28], intuitionistic fuzzy sets [29] and fuzzy language $[30,31]$. However, due to the complexity of the 3PL provider selection problem, the criterion type cannot be limited to one, but should rather be a mixture of two or more types [32]. It is a challenge to choose a 3PL provider under hybrid multi-criteria.

As 3PL provider selection issues become more complex, they essentially become a hybrid multi-criteria decision-making (HMCDM) problem [33]. Recently, a large number of HMCDM problems have appeared in the fields of social management, economic activities and large-scale engineering projects etc. [34-40]. However, there has been no application of such methods on the issue of 3PL provider selection. At present, the research on HMCDM has mainly focused on several hybrid types of decision information, such as real numbers, interval numbers, fuzzy numbers, intuitionistic fuzzy sets and linguistic variables etc. Wei [41] investigated the hybrid multi-criteria problems of real numbers, interval numbers and triangular fuzzy numbers, which obtained the ideal alternatives based on GRA. For the hybrid multi-criteria problem of real numbers and fuzzy linguistics, Ko [42] constructed a decision matrix by converting different information types into real numbers and used the QFD method to sort the alternatives. Zhao [43] et al. analyzed the hybrid decision information types of intuitionistic fuzzy sets, interval intuitionistic fuzzy sets and linguistic variables, and obtained the decision results by converting the linguistic variable information into triangular fuzzy numbers. Herrera [44] et al. converted numerical and linguistic variables into 2-tuple fuzzy linguistics and studied the HMCDM problem. Yucesan [45] et al. proposed a method for transforming fuzzy sets into real numbers, and used the TOPSIS method to rank the decision alternatives. Wang [46] et al. investigated the MCDM problem under the hybrid types of real numbers and fuzzy linguistics, and used Bonferroni mean operators to sort the decision alternatives. Deveci [47] designed a HMCDM approach combining the hybrid criterion types of hesitant and interval type 2 fuzzy sets to assess the service quality of airline companies. In view of the uncertainty in the decision-making process, Deveci [48] integrated the PCA and QFD methods with interval-valued intuitionistic fuzzy sets, aiming to evaluate service quality in public bus transportation. In recent years, the research on MCDM problems with hesitant fuzzy sets has become a hot topic [49-53]. However, the approach of HMCDM with hesitant fuzzy information has not yet been seen.

Because of the uncertainty of the evaluation circumstances and the incompleteness of the decision information in MCDM process, the subjective preference of DMs is often inconsistent with the evaluation results [54]. Interactive decision-making methods can build the model according to objective decision information and the subjective preference of DMs. By using the feedback, the difference between evaluation results and the preference of DMs can be reduced and, finally, an optimal alternative satisfying the requirements of the DMs can be obtained. Sakawa [55] first designed an interactive multi-objective $0-1$ program with fuzzy numbers to reflect the preferences of the DMs. The interactive decision-making method has attracted more and more scholars' attention recently, whose main results have focused on a single type of decision information, such as real numbers [56], triangular fuzzy numbers [57], linguistic variables [58,59], intuitionistic fuzzy sets [60], hesitant fuzzy sets [61] and probability hesitant fuzzy sets [62]. There has been little research on interactive decision-making methods under hybrid multi-criteria.

For the complexity and uncertainty of the 3PL provider selection problem, the criterion types are usually more than two and come with hesitant fuzziness. However, the existing interactive decision-making methods are limited to a single criterion type and the lack of hesitant fuzzy information. In this paper, which considers hesitant fuzzy sets, intuitionistic fuzzy sets and exact numerical values as hybrid multi-criteria, a novel interactive HMCDM method is proposed.

The main contributions of this work are as follows. Firstly, the proposed interactive method can solve the HMCDM problem under hybrid multi-criteria with hesitant fuzzy sets. Secondly, this method 
can directly use the original decision information to determine the weight and rank of the alternatives, so as to avoid the information loss caused by different criterion type conversions. Thirdly, in the interactive HMCDM method, the satisfaction function reflecting the DMs' preference is introduced to solve the problem where the evaluation results may be inconsistent with the DMs' subjective preference.

The rest of this paper is organized as follows. The selection criteria for 3PL providers and some related definitions are given in the next section. In Section 3, the satisfaction function of DMs for alternatives under hesitant fuzzy sets, intuitionistic fuzzy sets and real numbers is introduced. The interactive HMCDM method and its implementation procedure are developed based on the satisfaction function. In Section 4, a practical case of a Chinese airport company for 3PL provider selection is presented to illustrate the application of our models. Section 5 provides the sensitivity analysis to demonstrate the feasibility of the proposed approach. Some suggestions for future research are discussed in Section 6.

\section{Preliminaries}

\subsection{Selection Criteria for 3PL Providers}

For the selection criteria of 3PL providers, most of the research has mainly focused on cost, delivery, service quality, the ability to provide relevant information, financial condition, and so on. A brief list of the most critical criteria of 3PL provider selection is shown in Table 1.

Generally, the total assets, transport cost, delivery time, transport equipment and employee structure can be represented by real numbers, as shown in Table 1. However, the process of 3PL provider selection is characterized by the inaccuracy and uncertainty of practical criteria, as well as the appearance of confusion in human thinking. Since linguistic terms are preferred in 3PL provider selection, intuitionistic fuzzy sets are used for the linguistic ratings, such as customer satisfaction and user compatibility in Table 1. Not only the membership and non-membership but also the hesitation is used to characterize the vagueness and uncertainty in 3PL provider selection, where the evaluations of personalized service and technology level in Table 1 are represented by hesitant fuzzy sets.

Table 1. Key criteria for 3PL provider selection.

\begin{tabular}{|c|c|c|c|}
\hline Variable & Criterion & Definition & Authors \\
\hline $\mathrm{Y}_{1}$ & Total assets & $\begin{array}{l}\text { All assets owned by a logistics } \\
\text { enterprise }\end{array}$ & $\begin{array}{c}\text { Wang et al. [14], Prakash and Barua [16], } \\
\text { Huang et al. [18], Guarnieri et al. [63], Aguezzoul } \\
\text { and Aicha [64] }\end{array}$ \\
\hline $\mathrm{Y}_{2}$ & Transport cost & $\begin{array}{l}\text { Costs related to logistics } \\
\text { activities }\end{array}$ & $\begin{array}{c}\text { Stefan et al. [9], Yu et al. [12], Patricija and Suban [13], } \\
\text { Sremac et al. [15], Guarnieri et al. [63], } \\
\text { Zarbakhshnia et al. [65] }\end{array}$ \\
\hline $\mathrm{Y}_{3}$ & On time rate & Logistics delivery on time rate & $\begin{array}{c}\text { Stefan et al. [9], Patricija and Suban [13], } \\
\text { Sremac et al. [15], Guarnieri et al. [63], } \\
\text { Zarbakhshnia et al. [65], Li et al. [66] }\end{array}$ \\
\hline $\mathrm{Y}_{4}$ & Customer satisfaction & $\begin{array}{l}\text { Matching degree of customer } \\
\text { expectation and customer } \\
\text { experience }\end{array}$ & $\begin{array}{c}\text { Patricija and Suban et al. [13], Guarnieri et al. [63], } \\
\text { Aguezzoul and Aicha [64], Zarbakhshnia et al. [65], } \\
\text { Li et al. [66] Senthil et al. [67], Zouggari and } \\
\text { Benyoucef [68] }\end{array}$ \\
\hline $\mathrm{Y}_{5}$ & Personalized service & $\begin{array}{l}\text { Diversification degree of } \\
\text { logistics products and services }\end{array}$ & $\begin{array}{c}\text { Prakash and Barua [20], Guarnieri et al. [63], } \\
\text { Aguezzoul and Aicha [64], Zarbakhshnia et al. [65], } \\
\text { Li et al. [66], Senthil et al. [67], Zouggari and } \\
\text { Benyoucef [68] }\end{array}$ \\
\hline $\mathrm{Y}_{6}$ & User compatibility & $\begin{array}{l}\text { Degree of information sharing } \\
\text { with user }\end{array}$ & Shan [29], Feng et al. [69] \\
\hline$Y_{7}$ & Transport equipment & $\begin{array}{c}\text { Number of transportation } \\
\text { equipment }\end{array}$ & Shan [29], Feng et al. [69] \\
\hline $\mathrm{Y}_{8}$ & Employee structure & $\begin{array}{l}\text { Proportion of employees with } \\
\text { bachelor degree or above in the } \\
\text { total number of employees }\end{array}$ & $\begin{array}{l}\text { Sremac et al. [15], Huang et al. [18], } \\
\text { Guarnieri et al. [63], Zarbakhshnia [65], Li et al. [66], } \\
\text { Senthil [67] }\end{array}$ \\
\hline $\mathrm{Y}_{9}$ & Technology level & $\begin{array}{l}\text { Technical development ability to } \\
\text { monitor and implement } \\
\text { logistics activities }\end{array}$ & $\begin{array}{c}\text { Stefan et al. [9], Sremac et al. [15], Prakash and } \\
\text { Barua et al. [20], Guarnieri et al. [63], Aguezzoul and } \\
\text { Aicha [64], Arpachshad et al. [65] }\end{array}$ \\
\hline
\end{tabular}




\subsection{Related Definitions}

Hesitant fuzzy sets are very useful in dealing with situations where DMs have hesitancy in determining their preference of criteria for 3PL provider selection. Considering that some of the criteria for 3PL provider selection are in linguistic form, intuitionistic fuzzy sets are more comprehensively applied to the linguistic ratings.

Definition 1. [70] Let $T$ be a given finite set; a hesitant fuzzy set on $T$ is in terms of a function that, when applied to $T$, returns a subset of $[0,1]$, which can be represented as the following mathematical symbol:

$$
H=\left\{<t, h_{H}(t)>\mid t \in T\right\}
$$

where $h_{H}(t)$ is a set of values of $[0,1]$, denoting the possible membership degree of the element $t \in T$ to the set $H$. A hesitant fuzzy element $h_{H}(t)$ can be expressed as $h$ for short.

Definition 2. Let $H_{1}$ and $H_{2}$ be two hesitant fuzzy sets, and $l$ be denoted the number of hesitant fuzzy elements of $\mathrm{H}_{1}$ and $\mathrm{H}_{2}$. For illustration purposes, we show it with the same number of hesitant fuzzy elements. Then, the distance measured between $\mathrm{H}_{1}$ and $\mathrm{H}_{2}$ is defined as

$$
d\left(H_{1}, H_{2}\right)=\frac{1}{l} \sum_{\lambda=1}^{l}\left|h_{1}^{\lambda}-h_{2}^{\lambda}\right|
$$

Definition 3. Let $H_{1}$ and $H_{2}$ be two hesitant fuzzy sets; then, the distance measure $d\left(H_{1}, H_{2}\right)$ between $H_{1}$ and $\mathrm{H}_{2}$ should satisfy the following properties:

(1) $d\left(H_{1}, H_{2}\right) \geq 0$;

(2) $d\left(H_{1}, H_{2}\right)=0$ if and only if $H_{1}=H_{2}$;

(3) $d\left(H_{1}, H_{2}\right)=d\left(H_{2}, H_{1}\right)$.

Definition 4. [71] Let $T$ be a given finite set; an intuitionistic fuzzy set on $T$ can be defined as:

$$
\mathrm{I}=\left\{<t, \mu_{I}(t), v_{I}(t)>\mid t \in T\right\}
$$

where $0 \leq \mu_{I}(t) \leq 1$ and $0 \leq v_{I}(t) \leq 1$ represent the membership function and the non-membership function respectively, and $0 \leq \mu_{I}(t)+v_{I}(t) \leq 1$. For convenience, $\mu_{I}(t)$ and $v_{I}(t)$ are denoted by $\mu$ and $v$ respectively.

Definition 5. Let $I_{1}$ and $I_{2}$ be two intuitionistic fuzzy sets; then, the distance measure between $I_{1}$ and $I_{2}$ is defined as

$$
d\left(I_{1}, I_{2}\right)=\frac{1}{2}\left(\left|\mu_{1}-\mu_{2}\right|+\left|v_{1}-v_{2}\right|\right)
$$

Definition 6. The distance measure $d\left(I_{1}, I_{2}\right)$ between $I_{1}$ and $I_{2}$ should satisfy the following properties:

(1) $d\left(I_{1}, I_{2}\right) \geq 0$;

(2) $d\left(I_{1}, I_{2}\right)=0$ if and only if $I_{1}=I_{2}$;

(3) $d\left(I_{1}, I_{2}\right)=d\left(I_{2}, I_{1}\right)$.

Definition 7. Let $E_{1}$ and $E_{2}$ be two real numbers; the distance measure $d\left(E_{1}, E_{2}\right)$ between $E_{1}$ and $E_{2}$ is represented as

$$
d\left(E_{1}, E_{2}\right)=\left|E_{1}-E_{2}\right|
$$




\section{Interactive HMCDM Method}

\subsection{Description of a HMCDM Problem}

For a HMCDM problem, there is a discrete set of $\mathrm{m}$ alternatives $X=\left\{X_{1}, X_{2}, \cdots, X_{m}\right\}(\mathrm{m} \geq 2)$ and a finite set of $n$ criteria $Y=\left\{Y_{1}, Y_{2}, \cdots, Y_{n}\right\}(n \geq 3)$. For the alternative $X_{i}(i=1,2, \cdots, m)$ under the criteria $Y_{j}(j=1,2, \cdots, n)$, the evaluation results of the DMs can be known as $A_{i j}(i=1,2, \cdots, m ; m \geq$ $2 ; j=1,2, \cdots, n ; n \geq 3)$. The weight vector of criteria $Y_{j}$ can be represented by $w=\left(w_{1}, w_{2}, \cdots, w_{n}\right)^{T}$, where $0 \leq w_{j} \leq 1(j=1,2, \cdots, n ; n \geq 3)$ and $\sum_{j=1}^{n} w_{j}=1$.

If the set of all possible evaluations for the alternative $X_{i}$ under the criteria $Y_{j}$ can be considered as a hesitating fuzzy set $H_{i j}(i=1,2, \cdots, m ; m \geq 2 ; j=1,2, \cdots, n ; n \geq 3)$, then let $A_{i j}=H_{i j}=$ $\left\{h_{i j}{ }^{1}, h_{i j}{ }^{2}, \cdots, h_{i j}{ }^{l_{H}}{ }_{i j}\right\}$, where $l_{H_{i j}}$ is the number of hesitant fuzzy elements in $H_{i j}$. In general, the numbers of elements in two hesitant fuzzy sets $H_{1}$ and $H_{2}$ are different, so it is hard to compare different alternatives under the same criterion. For the hesitant fuzzy set with the lower elements number, the method [72] was used in this paper to add the largest hesitant fuzzy element into it until the number of elements in the two hesitant fuzzy sets is the same. For example, if $H_{1}=\{0.1,0.2,0.3\}$ and $H_{2}=\{0.4,0.5\}, H_{2}$ can be extended to $H_{2}=\{0.4,0.5,0.5\}$.

If the set of all possible evaluations for the alternative $X_{i}$ under the criteria $Y_{j}$ can be considered as an intuitionistic fuzzy set $I_{i j}(i=1,2, \cdots, m ; m \geq 2 ; j=1,2, \cdots, n ; n \geq 3)$, then let $A_{i j}=I_{i j}=\left(\mu_{i j}, v_{i j}\right)$, where $\mu_{i j}$ and $v_{i j}$ indicate the membership and non-membership degree of the alternative $X_{i}$ under the criteria $Y_{j}$ respectively.

If the evaluation results of the alternative $X_{i}$ under the criteria $Y_{j}$ are real numbers $E_{i j}(i=1,2, \cdots, m$; $m \geq 2 ; j=1,2, \cdots, n ; n \geq 3)$, then let $A_{i j}=E_{i j}$. In order to eliminate the dimension difference between real numbers, a normalization transformation [73] was introduced to make $0 \leq E_{i j} \leq 1$.

By using the above normalized hesitant fuzzy sets, intuitionistic fuzzy sets and real numbers, an initial decision matrix under hybrid multi-criteria can be written as

$$
A=\left[\begin{array}{cccc}
A_{11} & A_{12} & \cdots & A_{1 n} \\
A_{21} & A_{22} & \cdots & A_{2 n} \\
\vdots & \vdots & \ddots & \vdots \\
A_{m 1} & A_{m 2} & \cdots & A_{m n}
\end{array}\right]
$$

where $A_{i j}$ can be hesitant fuzzy set $H_{i j}$, intuitionistic fuzzy set $I_{i j}$ and real number $E_{i j}$.

\subsection{Setting the Ideal Solution of Hybrid Multi-Criteria}

In order to describe the satisfaction of the DMs for the alternative $X_{i}$ under the criteria $Y_{j}$, the positive ideal solution $A_{i j}{ }^{+}(i=1,2, \cdots, m ; m \geq 2 ; j=1,2, \cdots, n ; n \geq 3)$ and negative ideal solution $A_{i j}{ }^{-}(i=1,2, \cdots, m ; m \geq 2 ; j=1,2, \cdots, n ; n \geq 3)$ should be set.

When $A_{i j}$ is a hesitant fuzzy set, if the DMs are very satisfied with the alternative $X_{i}$ under the criteria $Y_{j}$, they will not hesitate to give their evaluation results " 1 ". At this time, the hesitant fuzzy element is 1 . When all of the hesitant fuzzy elements are 1 in the hesitant fuzzy set $A_{i j}$, $A_{i j}{ }^{+}=\{1,1, \cdots, 1\}$ is the positive ideal solution of the alternative $X_{i}$ under the criteria $Y_{j}$. If DMs are very dissatisfied with the alternative $X_{i}$ under the criteria $Y_{j}$, they will not hesitate to give their evaluation result " 0 " directly. When all of the hesitant fuzzy elements in the hesitant fuzzy set are 0 , $A_{i j}{ }^{-}=\{0,0, \cdots, 0\}$ is the negative ideal solution of the alternative $X_{i}$ under the criteria $Y_{j}$.

When $A_{i j}$ is an intuitionistic fuzzy set, if DMs believe that the alternative $X_{i}$ completely meets their requirements for criteria $Y_{j}$ and they have no objection, the intuitionistic fuzzy set is $(1,0)$. Therefore, the positive ideal solution of the alternative $X_{i}$ under the criteria $Y_{j}$ can be denoted by $A_{i j}{ }^{+}=(1,0)$. If DMs think that the alternative $X_{i}$ does not meet the requirements of DMs under criteria $Y_{j}$ at all and 
they give the negative evaluation results, the intuitionistic fuzzy set is $(0,1)$. Therefore, the negative ideal solution of the alternative $X_{i}$ under the criteria $Y_{j}$ can be represented as $A_{i j}{ }^{-}=(0,1)$.

When $A_{i j}$ is a real number, if the alternative $X_{i}$ fully meets the requirements of DMs under the criteria $Y_{j}$, the evaluation result of DMs is usually 1 . Therefore, the positive ideal solution of the alternative $X_{i}$ under the criteria $Y_{j}$ can be set to $A_{i j}{ }^{+}=1$. If an alternative $X_{i}$ does not meet DMs' requirements for the criteria $Y_{j}$ at all, the evaluation result is 0 . Therefore, the negative ideal solution of the alternative $X_{i}$ under the criteria $Y_{j}$ can be represented as $A_{i j}{ }^{-}=0$.

In a HMCDM process with hesitant fuzzy sets, intuitionistic fuzzy sets and real numbers, in order to describe the DMs' preference for the alternative under a different criterion, the satisfaction function can be constructed by using the weighted distance measures between the evaluation results, which are represented by positive and negative ideal solutions. The satisfaction function $S_{i}(w)(i=1,2, \cdots, m ; m \geq 2)$ for the given alternative $X_{i}$ under the criteria $Y_{j}$ with the weight vector $w=\left(w_{1}, w_{2}, \cdots, w_{n}\right)^{T}$ is defined as

$$
S_{i}(w)=\frac{(1-\theta) \sum_{j=1}^{n} w_{j} d\left(A_{i j}, A_{i j}{ }^{-}\right)}{\theta \sum_{j=1}^{n} w_{j} d\left(A_{i j}, A_{i j}{ }^{+}\right)+(1-\theta) \sum_{j=1}^{n} w_{j} d\left(A_{i j}, A_{i j}{ }^{-}\right)}
$$

where the parameter $\theta$ represents the DMs' preference, $0 \leq w_{j} \leq 1$, and $\sum_{j=1}^{n} w_{j}=1$. For an alternative $X_{i}$, when the evaluation results are of hesitant fuzzy sets, intuitionistic fuzzy sets and real numbers, $d\left(A_{i j}, A_{i j}^{+}\right)$and $d\left(A_{i j}, A_{i j}^{-}\right)$are distance measures between the positive and negative ideal solution of the evaluation results $A_{i j}$. The value of $d\left(A_{i j}, A_{i j}^{+}\right)$and $d\left(A_{i j}, A_{i j}^{-}\right)$can be calculated by the corresponding Equations (2), (4) and (5) respectively.

Usually the value of $\theta$ can be given by DMs in advance: $0<\theta<1 . \theta$ can be adjusted according to the DMs' preference. When $\theta>0.5$, it indicates that the DMs are pessimists. Under the same conditions, the higher the value of $\theta$, the lower the satisfaction. When $\theta<0.5$, it means that the DMs are optimistic. Satisfaction increases as the value of $\theta$ decreases under the same conditions.

\subsection{Interactive Decision-Making Process}

In a HMCDM process, DMs have their own subjective preferences for different alternatives, which leads to their satisfaction degree with some alternatives being too high and simultaneously too low with others. As our purpose is to select the alternative with the optimal satisfaction degree, several interactive HMCDM models, based on the satisfaction function, should be established to facilitate DMs to provide a new satisfaction degree or modify the previous satisfaction degree.

An initial interactive HMCDM model is constructed to obtain the initial satisfaction degree of DMs for the alternatives. Then, the first interactive HMCDM model is developed according to the limit of the initial satisfaction degree. The weights can be obtained by solving this model, and the satisfaction degree for the alternatives can be determined. If the satisfaction degree cannot be accepted by DMs, they have to adjust the limit of the satisfaction degree and reestablish a new interactive HMCDM model until the acceptable satisfaction is achieved. Through several interactions of the DMs' preference information in the models, the limit of the satisfaction degree can be modified and gradually improved until the acceptable satisfaction degree is finally obtained.

In order to obtain the initial satisfaction degree of the DMs, an initial interactive HMCDM model based on the satisfaction function $S_{i}(w)$ for the alternative $X_{i}$ is constructed, as shown in Equation (8): 


$$
\text { s.t. }\left\{\begin{array}{c}
\max \zeta \\
S_{i}(w) \geq \zeta \\
w=\left(w_{1}, w_{2}, \cdots, w_{n}\right)^{T} \in W \\
\sum_{j=1}^{n} w_{j}=1 \\
w_{j} \geq 0 ; i=1,2, \cdots, m ; m \geq 2 ; j=1,2, \cdots, n ; n \geq 3
\end{array}\right.
$$

where $w=\left(w_{1}, w_{2}, \cdots, w_{n}\right)^{T} \in W, W$ is a collection of weight vectors. Generally, there are five different representations of a weight vector [74], as follows:

(1) $\left\{w_{j_{1}} \geq w_{j_{2}}\right\}\left(j_{1} \neq j_{2}\right)$;

(2) $\left\{w_{j_{1}}-w_{j_{2}} \geq \alpha\right\}\left(j_{1} \neq j_{2} ; \alpha>0\right)$;

(3) $\left\{w_{j_{1}}-w_{j_{2}} \geq w_{j_{3}}-w_{j_{4}}\right\}\left(j_{1} \neq j_{2} \neq j_{3} \neq j_{4}\right)$;

(4) $\left\{w_{j_{1}} \geq \alpha w_{j_{2}}\right\}\left(j_{1} \neq j_{2} ; 0 \leq \alpha \leq 1\right)$;

(5) $\left\{\alpha \leq w_{j} \leq \alpha+\beta\right\}(0 \leq \alpha \leq \alpha+\beta \leq 1)$

where $\alpha$ and $\beta$ are parameters of a weight vector. The appropriate weight representation in Equation (8) will be selected.

The initial weight vector $w^{0}=\left(w_{1}^{0}, w_{2}{ }^{0}, \cdots, w_{n}^{0}\right)^{T}$ can be obtained by solving the above HMCDM model. Using the initial weight, the initial satisfaction degree of DMs for the alternative $X_{i}$ can be calculated according to Equation (7), denoted as $S_{i}\left(w^{0}\right)$. If the initial satisfaction degree of each alternative meets the expectation of the DMs, the optimal rank of alternatives satisfying DMs can be obtained. Otherwise, the limit of the satisfaction degree for the alternatives $\zeta_{i}^{t}(i=1,2, \cdots, m ; m \geq 2)$ can be set by means of the initial satisfaction function $S_{i}\left(w^{0}\right)$. Based on the limit, the $t^{\text {th }}$ interactive HMCDM model can be constructed, as shown in Equation (9):

$$
\begin{gathered}
\max \sum_{i=1}^{n} S_{i}\left(w^{t}\right) \\
S_{i}\left(w^{t}\right) \geq \zeta_{i}^{t} \\
w=\left(w_{1}{ }^{t}, w_{2}{ }^{t}, \cdots, w_{n}{ }^{t}\right)^{T} \in W \\
\sum_{j=1}^{n} w_{j}{ }^{t}=1 \\
w_{j}{ }^{t} \geq 0 ; i=1,2, \cdots, m ; m \geq 2 ; j=1,2, \cdots, n ; n \geq 3
\end{gathered}
$$

where $t(t \geq 1)$ is the number of the interactive process. The weight vector $w^{t}=\left(w_{1}{ }^{t}, w_{2}{ }^{t}, \cdots, w_{n}{ }^{t}\right)^{T}$ can be obtained by solving the interactive HMCDM Equation (9). If the model has no optimal solution, it means that some limits should be less than the current satisfaction degree of DMs. Thus, a new limit of satisfaction should be set and the interactive HMCDM model should be reestablished until the optimal weights can be solved by the model, and the ideal satisfaction degree for the alternative $X_{i}$ under the criteria $Y_{j}$ can then be obtained. Once the decision makers achieve their expected satisfaction, the iterative process of the Equation (9) can be completed.

Based on the above interactive HMCDM method, the process of 3PL provider selection can be divided into three phases. In phase I, it aims to collect and normalize the information of 3PL provider selection. Based on the decision matrix of hybrid multi-criteria in phase I, an initial interactive HMCDM model is constructed and used to obtain the initial satisfaction degree of DMs for the alternatives in phase II. The goal in phase III is to obtain the optimal weight vector and satisfaction degree by solving the interactive HMCDM models. The steps of the proposed interactive HMCDM method are shown in Figure 1. 


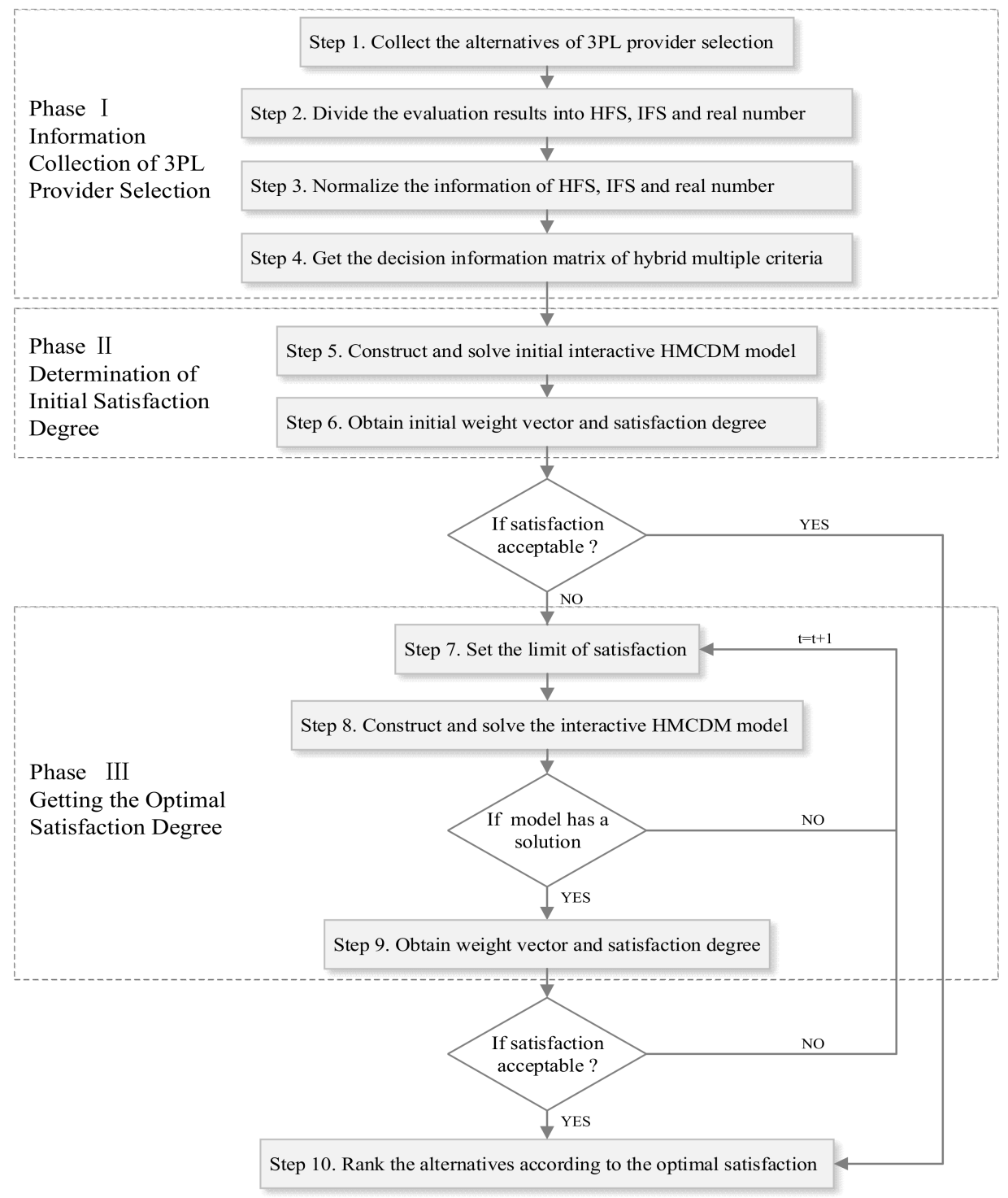

Figure 1. The steps of the proposed interactive HMCDM method.

\section{Case Study}

With the expansion of the airport and the increase in air cargo business, the existing 3PL providers have been unable to meet the needs of the airport's transportation. In this section, we consider an illustrative case in which a Chinese airport company wants to evaluate and select five potential 3PL providers, denoted as $\left\{X_{1}, X_{2}, X_{3}, X_{4}, X_{5}\right\} . X_{1}, X_{2}, X_{3}, X_{4}$ and $X_{5}$ are CS, CE, AC, H and S airline companies, respectively. The five companies are both passenger and cargo airlines, and they account for a major share of China's air logistics market. For convenience, total assets $Y_{1}$, transport cost $Y_{2}$, customer satisfaction $Y_{3}$, personalized service $Y_{4}$ and technology level $Y_{5}$ are taken as the criteria for 3PL provider selection.

As mentioned above, total assets $Y_{1}$ and transport cost $Y_{2}$ are usually expressed in real numbers that can be collected from the annual reports of the logistics company. For customer satisfaction $Y_{3}$, DMs prefer to give their evaluations in linguistic terms of belonging or non-belonging. For two criteria, personalized service $Y_{4}$ and technical level $Y_{5}$, the DMs are hesitant. It is hard to give a definite result and the DMs often give multiple evaluation values. Therefore, for the alternatives $X_{i}(i=1,2,3,4,5)$, the evaluations $A_{i 1}$ and $A_{\mathrm{i} 2}$ are real numbers under criterion $Y_{1}$ and $Y_{2}$ respectively, 
$A_{i 3}$ is an intuitionistic fuzzy set under criterion $Y_{3}$, and $A_{i 4}$ and $A_{i 5}$ are hesitant fuzzy sets under criteria $Y_{4}$ and $Y_{5}$ respectively.

In order to solve the 3PL provider selection problem under hybrid multi-criteria, the decision-making information is collected and normalized, for which the decision matrix $A=\left(A_{i j}\right)_{5 * 5}$ is shown in Table 2.

Table 2. The decision information under hybrid multi-criteria.

\begin{tabular}{cccccc}
\hline \multirow{2}{*}{ Alternative } & $\mathbf{Y}_{\mathbf{1}}$ & $\mathbf{Y}_{\mathbf{2}}$ & $\mathbf{Y}_{\mathbf{3}}$ & $\begin{array}{c}\text { Criteria } \\
\mathbf{Y}_{\mathbf{4}}\end{array}$ & $\mathbf{Y}_{\mathbf{5}}$ \\
\hline $\mathrm{X}_{1}$ & 0.57 & 0.45 & $(0.8,0.2)$ & $(0.7,0.75,0.8,0.9)$ & $(0.5,0.7,0.9,0.9)$ \\
$\mathrm{X}_{2}$ & 0.48 & 0.47 & $(0.6,0.4)$ & $(0.6,0.7,0.7,0.7)$ & $(0.3,0.5,0.5,0.5)$ \\
$\mathrm{X}_{3}$ & 0.66 & 0.46 & $(0.6,0.4)$ & $(0.7,0.75,0.8,0.8)$ & $(0.5,0.7,0.9,0.9)$ \\
$\mathrm{X}_{4}$ & 0.08 & 0.33 & $(0.8,0.2)$ & $(0.6,0.7,0.8,0.8)$ & $(0.5,0.7,0.9,0.9)$ \\
$\mathrm{X}_{5}$ & 0.01 & 0.51 & $(0.6,0.4)$ & $(0.1,0.2,0.2,0.2)$ & $(0.5,0.7,0.9,0.9)$ \\
\hline
\end{tabular}

In the process of the five 3PL provider selections, the importance of the criteria is investigated. It is found that the criterion 'total assets' was the most important, and that personalized service takes precedence over technology level. Customer satisfaction is more important than transport cost and personalized service. Transport cost is greater than average 0.2. Therefore, the relationship between the weights can be obtained as follows:

$$
w_{1}>w_{3}>w_{2} ; w_{3}>w_{4}>w_{5} ; w_{2}>0.2
$$

Since the satisfaction degree of the DMs for each alternative in actual 3PL provider selection is relatively low, $\theta=0.7$ can be taken in Equation (7). In order to obtain the initial satisfaction degree of the DMs for the alternatives, an initial interactive HMCDM model for 3PL provider selection can be constructed, as shown in Equation (10).

$$
\begin{gathered}
\max \zeta \\
\text { s.t. }\left\{\begin{array}{c}
\frac{0.1722 w_{1}+0.135 w_{2}+0.21 w_{3}+0.2363 w_{4}+0.225 w_{5}}{0.4704 w_{1}+0.52 w_{2}+0.42 w_{3}+0.385 w_{4}+0.4 w_{5}} \geq \zeta \\
\frac{0.1424 w_{1}+0.141 w_{2}+0.18 w_{3}+0.225 w_{4}+0.135 w_{5}}{0.5101 w_{1}+0.5120 w_{2}+0.46 w_{3}+0.43 w_{4}+0.52 w_{5}} \geq \zeta \\
\frac{0.1988 w_{1}+0.138 w_{2}+0.15 w_{3}+0.2288 w_{4}+0.225 w_{5}}{0.4349 w_{1}+0.516 w_{2}+0.5 w_{3}+0.395 w_{4}+0.4 w_{5}} \geq \zeta \\
\frac{0.0228 w_{1}+0.099 w_{2}+0.24 w_{3}+0.2175 w_{4}+0.225 w_{5}}{0.6696 w_{1}+0.568 w_{2}+0.38 w_{3}+0.41 w_{4}+0.4 w_{5}} \geq \zeta \\
\frac{0.004 w_{1}+0.153 w_{2}+0.18 w_{3}+0.0525 w_{4}+0.225 w_{5}}{0.6947 w_{1}+0.496 w_{2}+0.46 w_{3}+0.63 w_{4}+0.4 w_{5}} \geq \zeta \\
w_{1}>w_{3}>w_{2} ; w_{3}>w_{4}>w_{5} ; w_{2}>0.2 ; \sum_{j=1}^{5} w_{j}=1 \\
w_{j} \geq 0 ; i=1,2,3,4,5 ; j=1,2,3,4,5
\end{array}\right.
\end{gathered}
$$

The initial weight vector $w^{0}=\left(w_{1}^{0}, w_{2}{ }^{0}, w_{3}{ }^{0}, w_{4}{ }^{0}, w_{5}\right)^{0}=(0.24,0.22,0.23,0.16,0.15)^{T}$ and the initial satisfaction degree $S_{i}\left(w^{0}\right)=\left(S_{1}\left(w^{0}\right), S_{2}\left(w^{0}\right), S_{3}\left(w^{0}\right), S_{4}\left(w^{0}\right), S_{5}\left(w^{0}\right)\right)^{T}=$ $(0.4284,0.3331,0.4011,0.3028,0.2178)^{T}$ can be obtained by solving the Equation (10). Since the DMs are not yet satisfied with the initial satisfaction, they modify the limit of the satisfaction degree. Suppose that the modified limit is $\zeta_{i}^{1}=\left(\zeta_{1}^{1}, \zeta_{2}^{1}, \zeta_{3}^{1}, \zeta_{4}^{1}, \zeta_{5}^{1}\right)^{T}=(0.43,0.33,0.4,0.3,0.2)^{T}$; the first interactive HMCDM model can be set up as follows: 


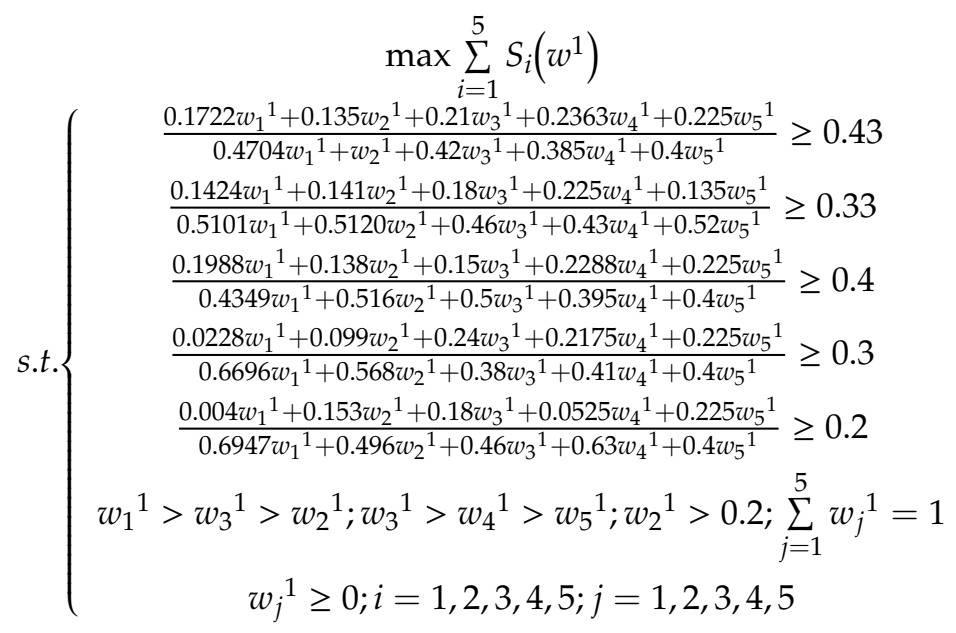

The weight vector $w^{1}=\left(w_{1}{ }^{1}, w_{2}{ }^{1}, w_{3}{ }^{1}, w_{4}{ }^{1}, w_{5}{ }^{1}\right)^{T}=(0.23,0.21,0.22,0.18,0.16)^{T}$ and the satisfaction degree $S_{i}\left(w^{1}\right)=\left(S_{1}\left(w^{1}\right), S_{2}\left(w^{1}\right), S_{3}\left(w^{1}\right), S_{4}\left(w^{1}\right), S_{5}\left(w^{1}\right)\right)^{T}=$ $(0.4348,0.3351,0.4077,0.3113,0.2177)^{T}$ can be obtained respectively by solving the Equation (11). If this satisfaction degree can be accepted by the DMs, it means the optimal satisfaction degree for five 3PL providers is obtained by the Equation (11). According to the priority relationship $S_{1}\left(w^{1}\right)>S_{3}\left(w^{1}\right)>S_{2}\left(w^{1}\right)>S_{4}\left(w^{1}\right)>S_{5}\left(w^{1}\right), X_{1}$ is the best among five 3PL providers, which is the right selection for the Chinese airport company.

\section{Sensitivity Analysis}

In this section, sensitivity analysis is carried out to show the performance of the proposed method, which can be divided into two parts. One part relates to the change of parameter $\theta$ and the other to the setting of the limit of satisfaction.

The cases of $\theta=0.1, \theta=0.2, \theta=0.8$ and $\theta=0.9$ are too extreme, therefore, we're not going to discuss them. Five scenarios are formed by parameter $\theta$ being increased by 0.1 in each scenario from 0.3-0.7. The sensitivity analysis of parameter $\theta$ can be shown in Table 3 .

Table 3. Sensitivity analysis of parameter $\theta$.

\begin{tabular}{ccccccc}
\hline \multirow{2}{*}{ Parameter } & \multicolumn{5}{c}{ Satisfaction } & Ranking Order \\
\cline { 2 - 5 } & $\boldsymbol{S}_{1}\left(\boldsymbol{w}^{0}\right)$ & $\boldsymbol{S}_{2}\left(\boldsymbol{w}^{0}\right)$ & $\boldsymbol{S}_{3}\left(\boldsymbol{w}^{0}\right)$ & $\boldsymbol{S}_{4}\left(\boldsymbol{w}^{0}\right)$ & $\boldsymbol{S}_{5}\left(\boldsymbol{w}^{0}\right)$ & \\
\hline$\theta=0.3$ & 0.8032 & 0.712 & 0.7848 & 0.7028 & 0.6026 & $X_{1}>X_{3}>X_{2}>X_{4}>X_{5}$ \\
$\theta=0.4$ & 0.7292 & 0.626 & 0.7067 & 0.6127 & 0.4933 & $X_{1}>X_{3}>X_{2}>X_{4}>X_{5}$ \\
$\theta=0.5$ & 0.6422 & 0.5334 & 0.6163 & 0.5133 & 0.3936 & $X_{1}>X_{3}>X_{2}>X_{4}>X_{5}$ \\
$\theta=0.6$ & 0.5448 & 0.4365 & 0.5171 & 0.4128 & 0.3021 & $X_{1}>X_{3}>X_{2}>X_{4}>X_{5}$ \\
$\theta=0.7$ & 0.4284 & 0.3331 & 0.4011 & 0.3028 & 0.2178 & $X_{1}>X_{3}>X_{2}>X_{4}>X_{5}$ \\
\hline
\end{tabular}

It can be seen from Table 3 that although the initial satisfaction degree is different for $\theta$ within a range of $0.3-0.7$, the ranking orders of five 3PL providers according to the satisfaction degree are the same; that is, $X_{1}>X_{3}>X_{2}>X_{4}>X_{5}$. It can also be seen that the smaller the value of $\theta$, the higher the satisfaction $S_{i}(w)$, and that the two values show the opposite trend. Figure 2 shows that a change in parameter $\theta$ does not affect the rank of the alternatives. 


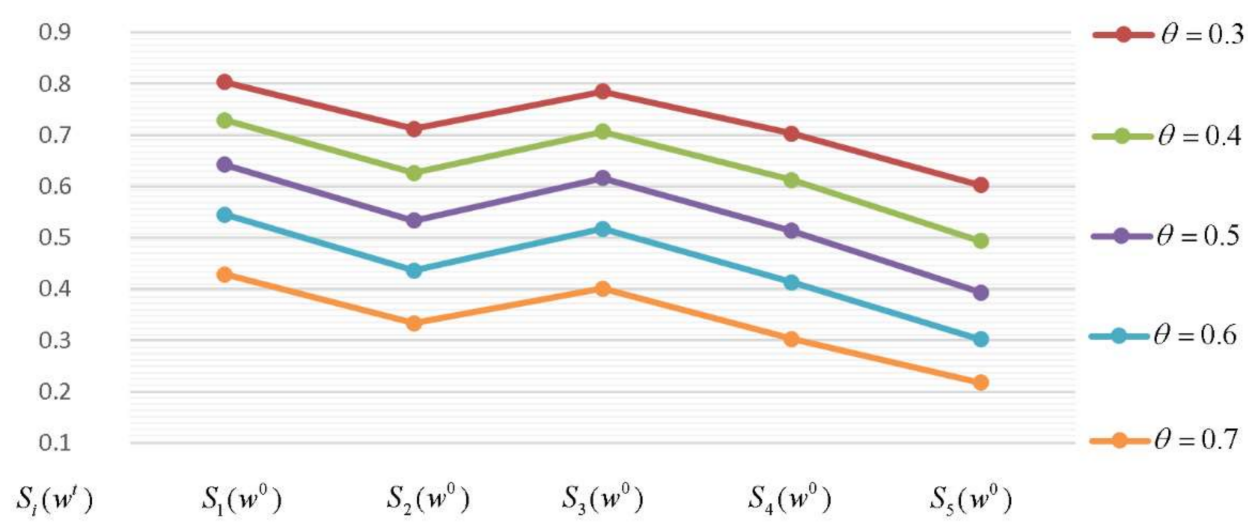

Figure 2. Sensitivity analysis of parameter $\theta$.

The second part of the sensitivity analysis is to investigate the influence of different limits of satisfaction on the optimal solution of the proposed model. In the above case study, for the initial satisfaction degree obtained by the Equation (10), according to the subjective preference of the DMs, two limits of the satisfaction degree are set to $\zeta_{i}{ }^{1}=(0.43,0.33,0.4,0.3,0.2)$ and $\zeta_{i}^{2}=(0.42,0.34,0.4,0.3,0.2)$ respectively. When $\theta=0.7$, the satisfaction degree corresponding to the above limits is calculated by Equation (11), which are shown in Table 4.

Table 4. Sensitivity analysis of the setting of the limit.

\begin{tabular}{ccccccc}
\hline Limit & \multicolumn{5}{c}{ Satisfaction } & Ranking Order \\
\hline \multirow{2}{*}{$\zeta_{i}{ }^{1}$} & $S_{1}\left(w^{1}\right)$ & $S_{2}\left(w^{1}\right)$ & $S_{3}\left(w^{1}\right)$ & $S_{4}\left(w^{1}\right)$ & $S_{5}\left(w^{1}\right)$ & \multirow{2}{*}{$X_{1}>X_{3}>X_{2}>X_{4}>X_{5}$} \\
& 0.4348 & 0.3351 & 0.4077 & 0.3113 & 0.2177 & \\
\hline \multirow{2}{*}{$\zeta_{i}{ }^{2}$} & $S_{1}\left(w^{2}\right)$ & $S_{2}\left(w^{2}\right)$ & $S_{3}\left(w^{2}\right)$ & $S_{4}\left(w^{2}\right)$ & $S_{5}\left(w^{2}\right)$ & \multirow{2}{*}{$X_{1}>X_{3}>X_{2}>X_{4}>X_{5}$} \\
& 0.4360 & 0.3413 & 0.4081 & 0.3106 & 0.2055 & \\
\hline
\end{tabular}

As can be seen from Table 4, although the limits of the satisfaction degree are different, the ranking order of the five 3PL providers remains the same; that is, $X_{1}>X_{3}>X_{2}>X_{4}>X_{5}$. This means that the different settings of the limit of satisfaction degree will not affect the optimal rank of alternatives.

\section{Conclusions}

Due to the lack of hesitant fuzzy information in the previous HMCDM methods and the limitation of the single criterion type in the interactive decision-making research, this paper proposes a novel interactive HMCDM approach to deal with a 3PL provider selection problem for which the types of criterion evaluation results are hesitant fuzzy sets, intuitionistic fuzzy sets and real numbers. First, the critical criteria for 3PL provider selection are set up. Then, it focuses on the issue of how to reduce the loss of decision information and express the subjective preference of DMs. For this reason, the positive and negative ideal solutions of the alternatives under hesitant fuzzy sets, intuitionistic fuzzy sets and real numbers are introduced respectively, and the satisfaction degrees of the DMs under hybrid multi-criteria circumstances are presented. In order to make the more reasonable decision, the proposed interactive HMCDM models for 3PL provider selection were developed. By using the interactive HMCDM approach, DMs can modify their preference information and make the most reasonable decision. Finally, an illustrative example of a Chinese airport company for 3PL provider selection was given, and the feasibility and practicality of the interactive HMCDM approach was demonstrated by sensitivity analysis.

The proposed method can directly use the original decision information to determine the weight and rank of the alternatives, which can avoid the information loss caused by different criterion type conversions. At the same time, the satisfaction degree limit can reflect the subjective preference of DMs, 
so as to solve the MCDM problem where the evaluation results are inconsistent with the subjective preference of the DMs.

In this paper, the importance of the DMs is considered to be the same in the proposed interactive HMCDM approach, and it can be applied to the hybrid multi-criteria group decision-making with the same importance under hesitation fuzzy sets, intuitionistic fuzzy sets and exact numerical value circumstances. However, in the actual group decision-making process, due to the different knowledge backgrounds and experience of DMs, as well as their understanding of the evaluation object, the DMs' importance in the evaluation process is different. In this paper, hesitant fuzzy sets, intuitionistic fuzzy sets and exact values were taken as hybrid multi-criteria. Other criteria, such as triangular fuzzy numbers, linguistic variables and probabilistic hesitant fuzzy sets, should be considered in the future HMCDM method under hybrid multi-criteria.

Therefore, this will also be our future direction of work. In further research, the interactive approach in this paper can be extended to hybrid multi-criteria group decision-making incorporating the different importance of DMs under hesitation fuzzy sets, intuitionistic fuzzy sets and real numbers. In this situation, the importance of each DM will also be reflected in the decision information. At the same time, whether the decision information can be expressed in more diverse ways is also a subject for future research.

Author Contributions: Authors Y.L. and P.Z. conceived and designed the model for research, pre-processed and analyzed the data and the obtained inference. Authors P.Z., F.Z. and L.L. processed the data collected and wrote the paper. The final manuscript has been read and approved by all authors. All authors have read and agreed to the published version of the manuscript.

Funding: This work was supported by National Natural Science Foundation of China Grant (No. 71672182, No. U1604262 and U1904211).

Acknowledgments: The authors are grateful to the editors and the anonymous reviewers for providing us with insightful comments and suggestions throughout the revision process.

Conflicts of Interest: The authors declare no conflict of interest.

\section{References}

1. Liu, C.; Lyons, A.C. An analysis of third-party logistics performance and service provision. Transp. Res. Part E Logist. Transp. Rev. 2011, 47, 547-570. [CrossRef]

2. $\mathrm{Xu}, \mathrm{Z}$.; Liu, Y.; Chen, M. Optimisation of partial collaborative transportation scheduling in supply chain management with 3PL using ACO. Expert Syst. Appl. 2017, 71, 173-191. [CrossRef]

3. Kampf, R.A.H.M. Optimization of Production Logistics. Adv. Sci. Technol. Res. J. 2018, 12, 151-156. [CrossRef]

4. Govindan, K.; Agarwal, V.; Darbari, J.D. An integrated decision making model for the selection of sustainable forward and reverse logistic providers. Ann. Oper. Res. 2019, 273, 607-650. [CrossRef]

5. Rajesh, R.; Pugazhendhi, S.; Ganesh, K.; Ducq, Y. Generic Balanced Scorecard Framework for Third Party Logistics Service Provider. Int. J. Prod. Econ. 2012, 140, 269-282. [CrossRef]

6. Gupta, R.; Sachdeva, A.; Bhardwaj, A. A Framework for the Selection of Logistic Service Provider Using Fuzzy Delphi and Fuzzy Topsis. Intell. Autom. Syst. Eng. 2011, 103, 189-202.

7. Boutkhoum, O.; Hanine, M.; Tikniouine, A. Multi-criteria Decisional Approach of the OLAP Analysis by Fuzzy Logic: Green Logistics as a Case Study. Arab. J. Sci. Eng. 2015, 40, 2345-2359. [CrossRef]

8. Yayla, A.Y.; Oztekin, A.; Gumus, A.T. A hybrid data analytic methodology for 3PL transportation provider evaluation using fuzzy multi-criteria decision making. Int. J. Prod. Res. 2015, 53, 6097-6113. [CrossRef]

9. Jovčić, S.; Průša, P.; Dobrodolac, M. A Proposal for a Decision-Making Tool in Third-Party Logistics (3PL) Provider Selection Based on Multi-Criteria Analysis and the Fuzzy Approach. Sustainability 2019, 11, 4236. [CrossRef]

10. Jung, H. Evaluation of Third Party Logistics Providers Considering Social Sustainability. Sustainability 2017, 9, 777. [CrossRef]

11. Qu, Q.; Wang, W.; Tang, M. A Performance Evaluation Study of Human Resources in Low-Carbon Logistics Enterprises. Sustainability 2017, 9, 632. [CrossRef] 
12. Yu, M.; Wang, C.; Ho, N. A Grey Forecasting Approach for the Sustainability Performance of Logistics Companies. Sustainability 2016, 8, 866. [CrossRef]

13. Bajec, P.; Tuljak-Suban, D. An Integrated Analytic Hierarchy Process-Slack Based Measure-Data Envelopment Analysis Model for Evaluating the Efficiency of Logistics Service Providers Considering Undesirable Performance Criteria. Sustainability 2019, 11, 2330. [CrossRef]

14. Wang, C.; Ho, H.T.; Luo, S. An Integrated Approach to Evaluating and Selecting Green Logistics Providers for Sustainable Development. Sustainability 2017, 9, 218. [CrossRef]

15. Sremac, S.; Stević, Ž.; Pamučar, D. Evaluation of a Third-Party Logistics (3PL) Provider Using a Rough SWARA-WASPAS Model Based on a New Rough Dombi Aggregator. Symmetry 2018, 10, 305. [CrossRef]

16. Prakash, C.; Barua, M.K. An analysis of integrated robust hybrid model for third-party reverse logistics partner selection under fuzzy environment. Res. Conserv. Recycl. 2016, 108, 63-81. [CrossRef]

17. Singh, R.K.; Gunasekaran, A.; Kumar, P. Third party logistics (3PL) selection for cold chain management: A fuzzy AHP and fuzzy TOPSIS approach. Ann. Oper. Res. 2018, 267, 531-553. [CrossRef]

18. Huang, Y.; Li, Q.; Wang, X. Lean Path for High-Quality Development of Chinese Logistics Enterprises Based on Entropy and Gray Models. Entropy 2019, 21, 641. [CrossRef]

19. Sasikumar, P.; Haq, A. Integration of closed loop distribution supply chain network and 3PRLP selection for the case of battery recycling. Int. J. Prod. Res. 2011, 49, 3363-3385. [CrossRef]

20. Prakash, C.; Barua, M.K. A combined MCDM approach for evaluation and selection of third-party reverse logistics partner for Indian electronics industry. Sustain. Prod. Consum. 2016, 7, 66-78. [CrossRef]

21. Sharma, S.K.; Kumar, V. Optimal selection of third-party logistics service providers using quality function deployment and Taguchi loss function. Benchmarking 2015, 22, 1281-1300. [CrossRef]

22. Chen, M.; Hsu, C.; Hsu, C. Ensuring the quality of e-shopping specialty foods through efficient logistics service. Trends Food Sci. Technol. 2014, 35, 69-82. [CrossRef]

23. Du, W.; Zhou, X.; Wang, C. Research on ecological logistics evaluation model based on BCPSGA-BP neural network. Multimed. Tools Appl. 2019, 78, 30271-30295. [CrossRef]

24. Li, Q.J. A Novel Logistics Supplier Selection Model Based on BP. Key Eng. Mater. 2011, 460-461, 735-740. [CrossRef]

25. Jin, F.W.; Xue, Q.Z.; Li, J.F. Identification of Security Status of Production Logistics System in Coal Mine Based on RS-SVM. J. Appl. Sci. 2013, 13, 5452-5457.

26. Vahdani, B.; Behzadi, S.S.; Mousavi, S.M. An artificial intelligence model based on LS-SVM for third-party logistics provider selection. Int. J. Ind. Math. 2015, 7, 301-311.

27. Pamucar, D.; Chatterjee, K.; Zavadskas, E.K. Assessment of third-party logistics provider using multi-criteria decision-making approach based on interval rough numbers. Comput. Ind. Eng. 2019, 127, $383-407$. [CrossRef]

28. Bulgurcu, B.; Nakiboglu, G. An extent analysis of 3PL provider selection criteria: A case on Turkey cement sector. Cogent Bus. Manag. 2018, 5, 1. [CrossRef]

29. Shan, L. Research on green logistics service providers selection based on intuitionistic language fuzzy entropy. J. Comput. 2012, 7, 540-546. [CrossRef]

30. Dhouib, D. An extension of MACBETH method for a fuzzy environment to analyze alternatives in reverse logistics for automobile tire wastes. Omega 2014, 42, 25-32. [CrossRef]

31. Wang, J.; Wang, J.Q.; Tian, Z.P. A multihesitant fuzzy linguistic multicriteria decision-making approach for logistics outsourcing with incomplete weight information. Int. Trans. Oper. Res. 2018, 25, 831-856. [CrossRef]

32. Zavadskas, E.K.; Mardani, A.; Turskis, Z. Development of TOPSIS Method to Solve Complicated Decision-Making Problems-An Overview on Developments from 2000 to 2015. Int. J. Inf. Technol. Decis. Mak. 2016, 15, 645-682. [CrossRef]

33. Akman, G.; Baynal, K. Logistics Service Provider Selection through an Integrated Fuzzy Multicriteria Decision Making Approach. J. Ind. Eng. 2014, 2014, 1-16. [CrossRef]

34. Jatoth, C.; Gangadharan, G.; Fiore, U. SELCLOUD: A hybrid multi-criteria decision-making model for selection of cloud services. Soft Comput. 2019, 23, 4701-4715. [CrossRef]

35. Kamble, S.J.; Singh, A.; Kharat, M.G. A hybrid life cycle assessment based fuzzy multi-criteria decision making approach for evaluation and selection of an appropriate municipal wastewater treatment technology. Euro Mediterr. J. Environ. Integr. 2017, 2, 9. [CrossRef] 
36. Ren, Z.; Xu, Z.; Wang, H. Multi-criteria group decision-making based on quasi-order for dual hesitant fuzzy sets and professional degrees of decision makers. Appl. Soft Comput. 2018, 71, 20-35. [CrossRef]

37. Rashid, T.; Faizi, S.; Xu, Z. ELECTRE-Based Outranking Method for Multi-criteria Decision Making Using Hesitant Intuitionistic Fuzzy Linguistic Term Sets. Int. J. Fuzzy Syst. 2018, 20, 78-92. [CrossRef]

38. Sarkar, S.; Pratihar, D.K.; Sarkar, B. An integrated fuzzy multiple criteria supplier selection approach and its application in a welding company. J. Manuf. Syst. 2018, 46, 163-178. [CrossRef]

39. Uygun, Ö.; Dede, A. Performance evaluation of green supply chain management using integrated fuzzy multi-criteria decision making techniques. Comput. Ind. Eng. 2016, 102, 502-511. [CrossRef]

40. Fan, Z.; Zhang, X.; Chen, F. Extended TODIM method for hybrid multiple attribute decision making problems. Knowl. Based Syst. 2013, 42, 40-48. [CrossRef]

41. Wei, G. Grey relational analysis model for dynamic hybrid multiple attribute decision making. Knowl. Based Syst. 2011, 24, 672-679. [CrossRef]

42. Ko, W. Construction of house of quality for new product planning: A 2-tuple fuzzy linguistic approach. Comput. Ind. 2015, 73, 117-127. [CrossRef]

43. Zhao, H.; Xu, Z.S.; Ni, M. Hybrid fuzzy multiple attribute decision making. Inf. Int. Interdiscip. J. 2009, 12, 1033-1044.

44. Herrera, F.; Martinez, L. An Approach for Combining Linguistic and Numerical Information Based on the 2-Tuple Fuzzy Linguistic Representation Model in Decision-Making. Int. J. Uncertain. Fuzziness Knowl. Based Syst. 2000, 8, 539-562. [CrossRef]

45. Yucesan, M.; Mete, S.; Serin, F. An Integrated Best-Worst and Interval Type-2 Fuzzy TOPSIS Methodology for Green Supplier Selection. Mathematics 2019, 7, 182. [CrossRef]

46. Wang, J.; Wei, G.; Wei, Y. Models for Green Supplier Selection with Some 2-Tuple Linguistic Neutrosophic Number Bonferroni Mean Operators. Symmetry 2018, 10, 131. [CrossRef]

47. Deveci, M.; Ozcan, E.; John, R. Interval type-2 hesitant fuzzy set method for improving the service quality of domestic airlines in Turkey. J. Air Transp. Manag. 2018, 69, 83-98. [CrossRef]

48. Deveci, M.; Öner, S.C.; Canitez, F. Evaluation of service quality in public bus transportation using interval-valued intuitionistic fuzzy QFD methodology. Res. Transp. Bus. Manag. 2019, 100387. [CrossRef]

49. Asan, U.; Kadaifci, C.; Bozdag, E. A new approach to DEMATEL based on interval-valued hesitant fuzzy sets. Appl. Soft Comput. 2018, 66, 34-49. [CrossRef]

50. Jiang, F. An Approach to Evaluating Three-Dimension Reconstruction Image Quality with Hesitant Fuzzy Information. Int. J. Sci. 2017, 4, 7. [CrossRef]

51. Ccedil, D.; Er, H.; Uuml, Y. Analyzing the Global Risks for the Financial Crisis after the Great Depression Using Comparative Hybrid Hesitant Fuzzy Decision-Making Models: Policy Recommendations for Sustainable Economic Growth. Sustainability 2018, 10, 3126.

52. Singh, S.; Lalotra, S. On generalized correlation coefficients of the hesitant fuzzy sets with their application to clustering analysis. Comput. Appl. Math. 2019, 38, 11. [CrossRef]

53. Liu, Y.; Jin, L.; Zhu, F. A Multi-Criteria Group Decision Making Model for Green Supplier Selection under the Ordered Weighted Hesitant Fuzzy Environment. Symmetry 2019, 11, 17. [CrossRef]

54. Lin, M.; Wang, H.; Xu, Z. TODIM-based multi-criteria decision-making method with hesitant fuzzy linguistic term sets. Artif. Intell. Rev. 2019, 4,1-25. [CrossRef]

55. Sakawa, M. Large Scale Interactive Multiobjective 0-1 Programming with Fuzzy Numbers; Physica-Verlag: Heidelberg, Germany, 2000.

56. Park, K.S.; Kim, S.H. Tools for interactive multiattribute decisionmaking with incompletely identified information. Eur. J. Oper. Res. 1997, 98, 111-123. [CrossRef]

57. $\mathrm{Xu}, \mathrm{Z} . \mathrm{S}$.; Chen, J. An interactive method for fuzzy multiple attribute group decision making. Inf. Sci. 2007, 177, 248-263. [CrossRef]

58. $\mathrm{Xu}, \mathrm{Z}$. An interactive procedure for linguistic multiple attribute decision making with incomplete weight information. Fuzzy Optim. Decis. Mak. 2007, 6, 17-27. [CrossRef]

59. $\mathrm{Xu}, \mathrm{Z}$. Interactive group decision making procedure based on uncertain multiplicative linguistic preference relations. J. Syst. Eng. Electron. 2010, 21, 408-415. [CrossRef]

60. Xu, Z. Intuitionistic Fuzzy Multiattribute Decision Making: An Interactive Method. IEEE Trans. Fuzzy Syst. 2012, 20, 514-525. 
61. Liao, H.; Xu, Z. Satisfaction Degree Based Interactive Decision Making under Hesitant Fuzzy Environment with Incomplete Weights. Int. J. Uncertain. Fuzziness Knowl. Based Syst. 2014, 22, 553-572. [CrossRef]

62. Ding, J.; Xu, Z.; Zhao, N. An interactive approach to probabilistic hesitant fuzzy multi-attribute group decision making with incomplete weight information. J. Intell. Fuzzy Syst. 2017, 32, 2523-2536. [CrossRef]

63. Guarnieri, P.; Sobreiro, V.A.; Nagano, M.S. The challenge of selecting and evaluating third-party reverse logistics providers in a multicriteria perspective: A Brazilian case. J. Clean. Prod. 2015, 96, 209-219. [CrossRef]

64. Aguezzoul, A. Third-party logistics selection problem: A literature review on criteria and methods. Omega 2014, 49, 69-78. [CrossRef]

65. Zarbakhshnia, N.; Soleimani, H.; Ghaderi, H. Sustainable third-party reverse logistics provider evaluation and selection using fuzzy SWARA and developed fuzzy COPRAS in the presence of risk criteria. Appl. Soft Comput. 2018, 65, 307-319. [CrossRef]

66. Li, Y.; Ying, C.; Chin, K. Third-party reverse logistics provider selection approach based on hybrid-information MCDM and cumulative prospect theory. J. Clean. Prod. 2018, 195, 573-584. [CrossRef]

67. Senthil, S.; Srirangacharyulu, B.; Ramesh, A. A robust hybrid multi-criteria decision making methodology for contractor evaluation and selection in third-party reverse logistics. Expert Syst. Appl. 2014, 41, 50-58. [CrossRef]

68. Zouggari, A.; Benyoucef, L. Simulation based fuzzy TOPSIS approach for group multi-criteria supplier selection problem. Eng. Appl. Artif. Intell. 2012, 25, 507-519. [CrossRef]

69. Feng, Y.; Zhang, Z.; Tian, G. A Novel Hybrid Fuzzy Grey TOPSIS Method: Supplier Evaluation of a Collaborative Manufacturing Enterprise. Appl. Sci. 2019, 9, 3770. [CrossRef]

70. Torra, V. Hesitant fuzzy sets. Int. J. Intell. Syst. 2010, 25, 529-539. [CrossRef]

71. Atanassov, K.T. Intuitionistic fuzzy sets. Fuzzy Sets Syst. 1986, 20, 87-96. [CrossRef]

72. Xu, Z.; Xia, M. Distance and similarity measures for hesitant fuzzy sets. Inf. Sci. 2011, 181, $2128-2138$. [CrossRef]

73. Ijadi Maghsoodi, A.; Ijadi Maghsoodi, A.; Mosavi, A. Renewable Energy Technology Selection Problem Using Integrated H-SWARA-MULTIMOORA Approach. Sustainability 2018, 10, 4481. [CrossRef]

74. Zhang, X.; Xu, Z.; Wang, H. Heterogeneous Multiple Criteria Group Decision Making with Incomplete Weight Information: A Deviation Modeling Approach. Inf. Fusion 2014, 25, 49-62. [CrossRef] 